\title{
In reply: Spinal anesthesia for Cesarean delivery in women with COVID-19 infection: questions regarding the cause of hypotension
}

\author{
Rong Chen, MD · Yun-yan Zhang, MD • Qin Zhou, MD • \\ Qing-tao Meng, MD, PhD
}

Received: 10 April 2020/Revised: 10 April 2020/Accepted: 10 April 2020/Published online: 27 April 2020

(C) Canadian Anesthesiologists' Society 2020

\section{To the Editor,}

The recent letter by Benhamou et al., ${ }^{1}$ has affirmed our experience $^{2}$ in anesthesia for Cesarean delivery in coronavirus disease (COVID-19) patients, and has also raised some questions. Now that the COVID-19 outbreak is in full swing in the world, we are willing to share our experience and are hoping to help every anesthesiologist in the frontline of the pandemic.

In our study, we described in the method section as to whether "Continuous epidural anesthesia or combined spinal-epidural anesthesia was the first choice to avoid endotracheal intubation". ${ }^{2}$ Nevertheless, because COVID19 was not fully understood in the early stage of the outbreak, we could not rule out the presence of severe acute respiratory syndrome coronavirus 2 (SARS-CoV-2) in the cerebrospinal fluid (CSF). To reduce the risk of viral spread, all 14 patients in our study received epidural anesthesia. Moriguchi et $a .^{3}$ verified our concern when they reported a case of viral encephalitis caused by SARS$\mathrm{CoV}-2$ and confirmed the presence of SARS-CoV-2 in the CSF using genome sequencing.

Rong Chen and Yun-yan Zhang contributed equally to this work

R. Chen, MD · Q. Zhou, MD · Q. Meng, MD, PhD ( $\varangle)$

Department of Anesthesiology, Renmin Hospital of Wuhan

University, Wuhan, China

e-mail: mengqingtao2018@126.com

Department of Anesthesiology, East Hospital, Renmin Hospital of Wuhan University, Wuhan, China

Y. Zhang, MD

Department of Anesthesiology, East Hospital, Renmin Hospital of Wuhan University, Wuhan, China
In our own study, ${ }^{2} 12$ of the women had perioperative hypotension-indeed, a high incidence of hypotension. Recently, Bhatraju et $a .^{4}$ reported a large proportion of critically ill COVID-19 patients presenting with shock that required vasopressor support and was directly related to COVID-19. One reason might be that SARS-CoV-2 binds to the angiotensin converting enzyme-II (ACE2) receptor. The ACE2 receptor is a cardio-cerebrovascular protective factor, which plays an important role in regulating blood pressure, in addition to have an anti-atherosclerosis mechanism. ${ }^{5}$ Because the duration of perioperative hypotension we reported was short (and not more than a $30 \%$ reduction from baseline), there was no apparent increase in end-organ damage. Perioperative hypotension was effectively treated using a combination of left lateral lying position, intravenous fluids, and vasopressor support (phenylephrine).

In addition, the three emergency Cesarean deliveries in our study had fetal distress when they entered the hospital and all received general anesthesia. As outlined by Benhamou et al., ${ }^{1}$ there was insufficient time for the anesthesiologist to inject an additional dose into the epidural catheter previously placed for labour analgesia early enough to obtain adequate surgical anesthesia. A multidisciplinary diagnosis and treatment model is the key for the anesthesiologist to don personal protective equipment and to prepare the needed equipment and medications before the patient entered the operating room, so that once the obstetrician completes the evaluation of the patient and communicates with the anesthesiologist, pediatrician and nurse, a rapid Cesarean delivery can be undertaken.

We hope that our experience can help ensure the safety of parturients and newborns during the COVID-19 
pandemic, and hope that it will help to protect frontline medical staff from SARS-CoV-2 infection.

Disclosures None.

Funding statement None.

Editorial responsibility This submission was handled by Dr. Hilary P. Grocott, Editor-in-Chief, Canadian Journal of Anesthesia.

\section{References}

1. Benhamou D, Meyer HK, Morau E, Chassard D, Mercier FJ. Spinal anesthesia for cesarean delivery in women with COVID-19 infection: questions regarding the cause of hypotension. Can J Anesth 2020; https://doi.org/10.1007/s12630-020-01663-y.
2. Chen R, Zhang Y, Huang L, Cheng B, Xia Z, Meng $Q$. Safety and efficacy of different anesthetic regimens for parturients with COVID-19 undergoing cesarean delivery: a case series of 17 patients. Can J Anesth 2020; . https://doi.org/10.1007/s12630-02001630-7.

3. Moriguchi T, Harii N, Goto J, et al. A first case of meningitis/ encephalitis associated with SARS-coronavirus-2. Int J Infect Dis 2020; . https://doi.org/10.1016/j.ijid.2020.03.062.

4. Bhatraju PK, Ghassemieh BJ, Nichols M, et al. Covid-19 in critically ill patients in the Seattle region - case series. N Engl J Med 2020; . https://doi.org/10.1056/NEJMoa2004500.

5. Miller AJ, Arnold AC. The renin-angiotensin system in cardiovascular autonomic control: recent developments and clinical implications. Clin Auton Res 2019; 29: 231-43.

Publisher's Note Springer Nature remains neutral with regard to jurisdictional claims in published maps and institutional affiliations. 